\title{
PELO RESGATE DE UM ENVELHECER SEM ESTIGMAS
}

\author{
César Augusto Sampaio
}

Universidade do Oeste Paulista - UNOESTE, Especialização em Gestão de Marketing e Comunicação, Presidente Prudente, SP. E-mail: caugusto67@hotmail.com

\section{RESUMO}

A finalidade desse artigo foi mostrar o idadismo e o papel das mídias de comunicação como promotoras de um envelhecimento com mais cidadania e menos preconceito contra os idosos. A partir dos discursos midiáticos, constatou-se que estes ainda são muito pautados na cultura da juventude. O que acaba acarretando no meio social uma "repulsão psicológica" por tudo que lembre decrepitude e mortalidade. Assim, todo o conhecimento do idoso bem como suas crenças, opiniões, ideologias, anseios e habilidades não costumam ser valorizados. Deve-se, portanto, desconstruir certos mitos e ideias ultrapassadas dessa fase da vida que insistem em habitar o imaginário popular. Para isso, as mídias de comunicação precisam estar mais engajadas nesse propósito, levando em consideração sobretudo as recomendações do Estatuto do Idoso e da Política Nacional do Idoso.

Palavras-chave: Velhice; Mídia; Preconceito; Envelhecimento; Idoso.

\section{FOR THE RESCUE OF AN AGING WITHOUT STIGMAS}

\section{ABSTRACT}

The purpose of this article was to show the idadismo and the role of the communication media as promoters of an aging with more citizenship and less prejudice against the elderly. From the media discourses, it was verified that these still are very ruled in the culture of the youth. What ends up causing in the social environment a "psychological repulsion" for everything that reminds decrepitude and mortality. Thus, all the knowledge of the elderly as well as their beliefs, opinions, ideologies, longings and abilities are not usually valued. It is therefore necessary to deconstruct certain myths and outdated ideas of this phase of life that insist on inhabiting the popular imagination. To this end, communication media need to be more engaged in this purpose, taking into account, in particular, the recommendations of the Statute of the Elderly and the National Policy of the Elderly.

Keywords: Old age; Media; Preconception; Aging; Old.

\section{INTRODUÇÃO}

As alterações da pirâmide etária brasileira, nas últimas décadas, transformaram um país preponderantemente jovem em adulto. E de agora em diante, o predomínio será o da população idosa, que vem aumentando e se tornará cada vez maior nos próximos anos.

Estimativas indicam que, em 2030, o Brasil contará com 41,5 milhões de pessoas com 60 anos ou mais de idade, ultrapassando o número de crianças entre 0 a 14 anos (39,2 milhões). A arrancada desse crescimento continuará e, para 2050, são esperados 66,5 milhões de seniores, revela o mais recente estudo do $\operatorname{IBGE}^{1}$ (2016).

De fato, o terceiro milênio está trazendo uma nação mais longeva, mas será que a sociedade está preparada para lidar com esse fenômeno social sem precedentes?

\footnotetext{
${ }^{1}$ Instituto Brasileiro de Geografia e Estatística

Colloquium Socialis, Presidente Prudente, v. 01, n. Especial 2, Jul/Dez, 2017, p.809-814. DOI: 10.5747/cs.2017.v01.nesp2.s0232
} 
A priori, constata-se que os idosos estão vivendo de maneira mais produtiva e sem descuidar da aparência e da saúde. É possível mesmo verificar, sobretudo pelas mídias de massa, que muitos deles têm voltado à faculdade, participam de cursos de capacitação, aprendem novas línguas, dançam, organizam-se em grupos para viajar e defender seus direitos, e assim por diante.

Contudo, numa análise mais criteriosa, percebe-se que tal cenário não abrange amplas camadas desse perfil populacional. Pelo contrário, elas ainda convivem com o preconceito que acaba levando ao abandono, aos maus tratos, à exclusão da vida profissional, familiar e cidadã de muitos idosos.

O que o artigo busca saber então é o papel das mídias de comunicação como agentes capazes de promover um envelhecimento que possa resgatar a cidadania dessa faixa etária, livre de preconceitos e estereótipos.

Afinal, elas são formadas por produtores midiáticos que influenciam o modo das pessoas conceberem o mundo, fazendo com que os sujeitos sociais busquem nas expressões midiáticas subsídios para formar a sua imagem e simbologias da realidade, esclarece Wolf (1997).

\section{METODOLOGIA}

Essa pesquisa foi de natureza bibliográfica e documental. A primeira garante um reforço paralelo que ajuda o cientista nas suas análises de pesquisas e manipulação de suas informações. O que proporciona formas de se definir e resolver tanto problemas conhecidos, como também de se explorar novas áreas em que eles ainda não foram suficientemente cristalizados, conforme Marconi e Lakatos (2003).

Ou seja, não se trata apenas de uma mera repetição do que já foi dito ou escrito antes sobre certo assunto, mas, sim, de uma pesquisa que favorece o exame de um tema sob novo enfoque de abordagem, chegando a conclusões inovadoras.

Já a segunda, pesquisa documental, ainda de acordo com as autoras citadas acima, referese à coleta de dados feita em diversos documentos denominados de fontes primárias. Isso possibilita colher informações prévias sobre o campo de interesse, resultando numa melhor compreensão do objeto de estudo.

\section{RESULTADOS}

Hoje em dia, os imperativos das leis de mercado não se restringem somente a produtos e serviços em si, mas englobam os sujeitos que passaram também a ser colocados como objetos de consumo.

O indivíduo autônomo de nossos tempos não coincide com o conjunto preestabelecido de obrigações simbólicas, por isso ele é obrigatoriamente narcísico: sua consciência subjetiva, em princípio, não é o peso da herança recebida, mas o fruto de suas contínuas tentativas de se manter desejável aos olhos dos outros (CALLIGARIS, 1996, p. 43).

Nessa perspectiva, envelhecer então se transforma em algo assustador, já que a palavra carrega entre os seus sinônimos a carga negativa de "tornar-se desusado", "inútil", "decadente" e "declinante".

A verdade é que essas percepções acabam se convertendo em atitudes generalizadas de discriminação para com aqueles indivíduos de mais idade. Um relatório recente da $\mathrm{OMS}^{2}$ (2016), baseado em 57 países pelo mundo, mostra que o preconceito de idade continua extremamente comum, sendo que a maioria das pessoas desconhece completamente os estereótipos subconscientes que elas carregam sobre os mais velhos.

\footnotetext{
2 Organização Mundial da Saúde.

Colloquium Socialis, Presidente Prudente, v. 01, n. Especial 2, Jul/Dez, 2017, p.809-814. DOI: 10.5747/cs.2017.v01.nesp2.s0232
} 
Tanto é assim, que a campanha internacional do dia do idoso, daquele ano, foi uma exortação contra o preconceito de idade em favor de um envelhecimento sem estigmas, na tentativa de reverter o conceito negativo que ainda impera acerca da imagem do velho.

A finalidade é dar um novo sentido para essa palavra e resgatar a cidadania de pessoas marginalizadas pela idade. Não se trata de negar o direito a envelhecer, o que seria um tipo de violência simbólica aos que já passaram dos 60 . Mas, sim, de incutir um significado para a velhice como algo precioso, indestrutível, que perdura.

O desafio, porém, está em como alcançar tal objetivo diante dos ditames de uma cultura capitalista focada na produção e no descartável. Quando se sabe, por exemplo, que a sua lógica para fazer girar uma economia cada vez mais competitiva é a agilidade, a independência e a autonomia funcional pela busca de melhores resultados.

Numa época marcada pela ansiedade e impaciência, "torna-se incompatível e até perda de tempo aceitar o ritmo mais lento por parte dos idosos", complementa Oliveira (1999, p, 46).

Diante desse panorama, caberia perguntar se, de fato, as mídias de comunicação estariam comprometidas com a valorização ou a negação da velhice. Mesmo porque elas são responsáveis pela representação simbólica dos mais diversos grupos sociais no imaginário popular.

\section{DISCUSSÃO}

O século XXI vem revolucionando comportamentos por intermédio das múltiplas formas de interação da era digital. São novas configurações familiares, quebra de conceitos morais, além de uma avalanche de mídias e informações que instituem outros modos de pensar, ser e agir.

Mas, apesar de todos os avanços, o caráter depreciativo da velhice permanece uma realidade presente no dia a dia. Trata-se de estigmas sociais que perduram na cultura brasileira, seja nas interações diárias, seja no sistema midiático, e são repassados através de gerações mediante o contexto sócio-histórico, inclusive até com aceitação dos próprios idosos dessa vitimização social, no dizer de Stacheski (2014).

Sibilia (2012, p. 97) é taxativa em afirmar que na construção dos discursos midiáticos a velhice ainda é um direito negado: “...a velhice é censurada como se fosse algo obsceno e vergonhoso, que deveria permanecer oculto, fora de cena."

Trata-se de uma declaração que pode ser facilmente constatada na televisão, onde artistas e famosos costumeiramente são submetidos às correções das ditas "imperfeições" de idade. É que manchas, rugas, sinais de adiposidades, flacidez e todas as marcas naturais do tempo não podem ser toleradas, devendo logo ser retocadas pelos mais modernos softwares digitais de edição de imagem.

Algumas celebridades chegam até a contrariar o bom senso e a prudência e partem para procedimentos estéticos bastante arriscados. Não faltam também programas de TVs, ao estilo reality shows, que frequentemente oferecem aos seus participantes a mais completa renovação da sua imagem pessoal.

Enfim, o que se verifica é uma verdadeira pedagogia social da mídia em prol do rejuvenescimento, segundo Castro (2015). Veicula-se abundantemente um rol de preceitos sobre tratamentos estéticos e manutenção corporal, regras de comportamento, de consumo e de bens específicos, tudo com a promessa de evitar ou retardar o envelhecimento.

A própria generalização dos eufemismos "terceira idade", "boa idade", "feliz idade", "futuridade", "melhor idade" etc., estariam sendo apropriados estrategicamente pelos agentes midiáticos para se construir uma nova imagem do idoso sob a égide da vitalidade, da força e beleza da juventude.

Aliás, Debert já demonstrava, em 2004, a sua preocupação com a cultura da terceira idade, a qual estaria sendo pautada por um conjunto de valores e práticas voltadas para mostrar que é possivel ser jovem em qualquer idade. 
Quer dizer, isso não deixaria de ser uma forma de discriminação internalizada, na medida em que negaria ao sujeito o direito de envelhecer, fazendo com que ele busque parecer mais jovem a fim de ser aceito e acolhido, disfarçando suas características, seus atributos e sua identidade, conforme Minayo e Coimbra (2011).

Assim, todo o conhecimento que poderia ser repassado pelo idoso, bem como suas crenças, opiniões, ideologias, anseios e habilidades deixariam de ser valorizados. Acontece que os constantes apelos sugeridos pelos sistemas midiáticos acerca da manutenção de um corpo belo e jovem acabariam criando, entre os jovens, uma "repulsão psicológica" por tudo que lembre decrepitude e mortalidade (MARQUES; MATOS, 2011).

A rejeição da velhice já se transformou até numa nova patologia da ciência psiquiátrica conhecida como gerontofobia, isto é, a aversão ou o medo de envelhecer e de tudo que se relaciona com o envelhecimento.

Não há como reverter esse quadro senão pela desconstrução de certos mitos e ideias ultrapassadas a respeito dele, que ainda insistem em habitar o imaginário popular.

A começar pela falsa concepção de que todos os idosos são iguais. Pelo contrário, envelhecer é uma experiência bastante heterogênea, variando conforme o caráter social, histórico e cultural de cada indivíduo. Basta observar a capacidade física e mental de alguns adultos maiores de 80 anos, que pode chegar ao nível da de muitos jovens com 20, segundo relatório da Organização Mundial da Saúde (OMS, 2015).

Isso implica dizer também que nem todos os velhos são frágeis e dependentes como geralmente se imagina. Até porque a maioria dos problemas de saúde decorrente da idade avançada está associada a doenças crônicas. Contudo, elas não impedem que o idoso possa gerir sua própria vida e cuidar-se de forma totalmente independente (HERÉDIA, 2014).

Outra forma de preconceito bastante comum surge por razões econômicas, na crença de que a idade avançada é sinal de incompetência e improdutividade, salienta Neri (2007). Nele, os idosos valeriam menos nas trocas sociais e passariam a representar um fardo econômico para sociedade.

A OMS (2015), porém, refuta essa ideia com dados que mostram a relação entre custos e contribuições dos idosos em algumas partes do mundo.

No Reino Unido, por exemplo, enquanto as despesas com pensões, bem-estar e serviços de saúde aumentarão em $59 \%$ até 2030 , as contribuições feitas por meio de impostos serão bem maiores e chegarão a $82 \%$. Vale lembrar também dos valiosos e crescentes recursos financeiros que os velhos podem fornecer na área do consumo.

E mesmo em países menos desenvolvidos, como no caso do continente africano, a idade média dos pequenos agricultores é de mais de 60 anos. 0 que mostra a importância crucial dessas pessoas na manutenção alimentar de seus povoados, assegura a OMS (2015).

Ainda que possa haver desvantagens funcionais da mão-de-obra idosa, mesmo assim ela pode ser perfeitamente produtiva nos dias de hoje, tendo em vista que todo o progresso tecnológico da era digital vem diminuindo substancialmente a exigência física para o exercício do trabalho.

Ademais, não faltariam casos das inúmeras formas de contribuição dos idosos em prol do desenvolvimento, inclusive em tarefas menos tangíveis economicamente, como no apoio emocional naqueles momentos de estresse, ou no aconselhamento relacionados a problemas desafiadores.

Tomar conhecimento de todos os aspectos arrolados acima é o ponto de partida para não se cair no senso comum de uma visão estereotipada e preconceituosa do envelhecimento.

Trata-se de uma situação em que as mídias de comunicação assumem papel imprescindível. Algo que o próprio Estatuto do Idoso reconhece no seu artigo 24, ao enfatizar que os meios de comunicação precisam manter espaços destinados ao público dessa faixa etária, 
levando conteúdo educativo, informativo e cultural a respeito do envelhecimento e de seus aspectos biopsicossociais.

De maneira geral, verifica-se que nas TVs abertas existem programas para vários segmentos: crianças, adolescentes, esportistas, donas de casa, menos para o grupo dos idosos.

E não é por falta de recomendação que isso ocorre. A Política Nacional do Idoso, por exemplo, também estabelece, no seu artigo 10, a importância de programas educativos, especialmente nos meios de comunicação, voltados para o esclarecimento e compreensão dos processos do envelhecimento.

Em suma, transcender estereótipos, mitos e ideias preconcebidas sobre velhice precisa envolver um maior reconhecimento dos pontos fortes, das contribuições e do valor criativo de mulheres e homens idosos. Preceito este que deve nortear os discursos dos veículos de comunicação, ainda tão pautados na valorização da cultura da juventude.

\section{CONCLUSÃO}

A elaboração desse artigo apresentou a questão do idadismo e o papel das mídias de comunicação como promotoras de um envelhecimento com mais cidadania e menos preconceito contra os idosos.

Constatou-se que o caráter depreciativo da velhice ainda é uma realidade nos dias de hoje. São estigmas sociais que perduram na cultura brasileira, seja nas interações diárias, seja no sistema midiático, e costumam ser repassados através de gerações mediante o contexto sóciohistórico, até mesmo com a aceitação dos próprios idosos dessa vitimização social.

Todo o conhecimento dessas pessoas adquirido ao longo dos anos, bem como suas crenças, opiniões, ideologias, anseios e habilidade geralmente não são valorizados. Por causa dos constantes apelos sugeridos pelos sistemas midiáticos acerca de um corpo belo e jovem, cria-se no meio social uma "repulsão psicológica" por tudo que possa lembrar decrepitude e mortalidade.

Para reverter tal situação é necessário desconstruir certos mitos e ideias ultrapassadas sobre essa fase da vida. A começar pela falsa concepção de que todos os idosos são iguais. Além disso, cumpre ressaltar que nem todos os velhos são frágeis e dependentes e, muito menos, que eles possam ser um fardo econômico para a sociedade.

Enfim, tomar conhecimento desses aspectos supracitados já ajuda a não cair no senso comum de uma visão estereotipada e preconceituosa do envelhecimento. Algo para o qual as mídias de comunicação precisam estar mais engajadas, seguindo com mais rigor as recomendações do Estatuto do Idoso e da Política Nacional do Idoso.

\section{REFERÊNCIAS BIBLIOGRÁFICAS}

CALLIGARIS, Contardo. Crônicas do individualismo cotidiano. São Paulo: Editora Ática, 1996.

CASTRO, Gisela G. S. Precisamos discutir o idadismo na comunicação. In: Revista Comunicação \& Educação. Ano XX, número 2, jul/dez 2015.

DEBERT, Guita Grin. A Reinvenção da Velhice: socialização e processos de reprivatização do envelhecimento. São Paulo: Editora da Universidade de São Paulo, 2004.

ESTATUTO DO IDOSO. Legislação sobre o idoso. Câmara dos deputados. 3a edição, 2013. Disponível em: <http://www2.camara.leg.br/a-camara/programas institucionais/inclusao-social-eequidade/acessibilidade/legislacao-pdf/Legislaoidoso.pdf > Acesso em 6 Julho, 2017.

HERÉDIA, Vânia B. M. O envelhecimento no Século XXI e os desafios das políticas públicas. In: Vida Saudável: múltiplos olhares e múltiplos saberes. Ilhéus, Bahia: Editora da UESC, 2014. 
IBGE (Instituto Brasileiro de Geografia e Estatística). Brasil: uma visão geográfica e ambiental no início do século XXI. Rio de Janeiro: Editor IBGE, coordenação de geografia, 2016. Disponível em: <http://biblioteca.ibge.gov.br/biblioteca-catalogo?id=297884\&view=detalhes > Acesso em 18 Setembro 2016.

MARCONI, Marina de Andrade; LAKATOS, Eva Maria. Fundamentos da Metodologia Científica. 5 ed. São Paulo: Atlas, 2003.

MARQUES, Ângela; MATOS, Heloíza. Comunicação e Política: capital social, reconhecimento e deliberação pública. São Paulo: Summus, 2011.

MINAYO, Maria Cecília de Souza; COIMBRA, Carlos E. A. Antropologia, Saúde e Envelhecimento. Rio de Janeiro: FIOCRUZ, 2a reimpressão, 2011.

NERI, Anita L. Idosos no Brasil: vivências, desafios e expectativas na terceira idade. São Paulo: Editora Fundação Perseu Abramo, edições SESC SP, 2007.

OMS (Organização Mundial da Saúde). World Health Organization: World report on Ageing and Health. Genebra, Suíça, 2015. Disponível em: <http://apps.who.int/iris/bitstream/10665/186463/1/9789240694811_eng.pdf?ua=1> Acesso em: 5 Junho 2017.

OMS (Organização Mundial da Saúde). Discrimination and negative attitudes about ageing are bad for your health. Genebra, 2016. Disponível em: <http://www.who.int/mediacentre/news/releases/2016/discrimination-ageing-youth/en/> Acesso em: 9 Setembro, 2016.

OLIVEIRA, R. C. S. Terceira Idade: do repensar dos limites aos sonhos possíveis. Campinas: Papirus, 1999.

POLÍTICA NACIONAL DO IDOSO. Brasília, 2010. Disponível em: <http://www.mds.gov.br/webarquivos/publicacao/assistencia_social/Normativas/politica_idoso.p df > Acesso em 3 junho 2017.

SIBILIA, Paula. $\mathbf{O}$ corpo velho como uma imagem com falhas: a moral da pele lisa e a censura midiática da velhice. In: Revista Comunicação, mídia e consumo. São Paulo ano 9, vol. 9, no 26, p. 83-114, nov. 2012.

STACHESKI, Denise Regina. Comunicação Pública: Idosos e representações sociais. Florianópolis: Combook, 2014.

STAMATO, Cláudia. Idosos, tecnologias de comunicação e socialização. Rio de Janeiro, R.J., 2014. Disponível em: <http://www.dbd.puc-rio.br/pergamum/ tesesabertas/ 1011904_2014_ completo.pdf> Acesso em: 16 Setembro 2015.

WOLF, Mauro. Teorias da Comunicação. Lisboa: Presença, 1997. 